\title{
A Review of Research on the Oppositional Behavior of Brand Fans
}

\author{
Jiada Chen ${ }^{1, *}$, Simin $\mathrm{Ma}^{2}$ \\ ${ }^{1}$ Department of Marketing, School of Management, Jinan University, Guangzhou \\ ${ }^{2}$ Department of Marketing, School of Management, Jinan University, Guangzhou \\ ${ }^{*}$ Corresponding author e-mail: 528053213@qq.com
}

\begin{abstract}
Consumers are active in their favourite brand communities and go to competing brands' communities to express their love for their own brand, mock the competing brands, and so on. This phenomenon is known as brand fan antagonism or oppositional loyalty. In recent years, brand fan antagonism has become more frequent, yet academic research on this type of behavior is scarce, and brands' perception of brand antagonism is limited. This paper systematically reviews the existing literature to provide a more comprehensive analysis of brand fan confrontation behavior. Firstly, it introduces the concept of brand fan confrontation behavior. Secondly, it summarises the types of brand fan confrontation behavior and the factors that lead to the different types. Thirdly, it summarises the research related to brand fan confrontation behavior at home and abroad, and finally, it proposes the direction of future research. It is intended to enrich the academic research on this behavioral theory and provide brand marketing insights.
\end{abstract}

Keywords: oppositional loyalty, Brand competition, Brand loyalty, Brand community.

\section{INTRODUCTION}

It is common for consumers of a brand to attack its competitors on social media, and this kind of fanboy rivalry is prevalent in the marketplace, spanning many industries, including mobile phones, cars, and computers. For example, consumers of Xiaomi, "Mi Fan," and Huawei, "Flower Fan," often disagree on the merits of their mobile phone products; the 100-year battle between Coca-Cola and Pepsi [1]; the advertising war between BMW and Mercedes-Benz; the PK between McDonald's and KFC; etc. PK, etc.

When one of these brands is mentioned, we can quickly associate it with a competitor brand, which indicates that this type of antagonistic behavior has become a widespread phenomenon in the marketplace, slowly moving from the individual to the group and then to almost every consumer. This behavioral phenomenon has also been the subject of extensive scholarly research and is known as brand-confrontation loyalty. Unlike traditional loyalty theory, which is limited to the relationship between a consumer and a brand, brand oppositional loyalty theory places consumer behavior and brands together in a competitive situation to analyze the behavior of consumers with two competing brands and the patterns therein predict consumers' purchasing decisions. Related research helps brands maintain and strengthen their fan communities, reduce brand-customer churn and develop loyal users.

The importance of brand fan confrontation in the marketplace has attracted the attention of scholars, but in general, there is little research on the classification of brand fan confrontation. Therefore, this paper systematically composes the research results on brand fan confrontation. First, we introduce the concept of brand fan confrontation, summarize the types of brand fan confrontation and its causative factors, and analyze the concept from several aspects. Finally, we propose future research directions to provide a basis for classifying the forms of brand fan confrontation, laying the foundation for subsequent research, and providing suggestions and guidance for brands.

\section{THE CONCEPT OF BRAND FAN CONFRONTATION}

Brand fan confrontation, known as oppositional brand loyalty, refers to members of a brand community who avoid or refuse to use a competing brand's products. It can also be described as a phenomenon in which consumers of a brand not only express approval/love for that brand, but also hold negative/oppositional views 
towards its competing brand, or even exhibit hostile behaviors such as using profanity to dislike/ridicule/sarcasm each other [2][3]. The earliest conceptualization of this behavior comes from[4]. Hamer introduced 'oppositional brand loyalty, which is supported in the literature by the antagonism between Mac users and PC users and Saab owners and Volvo. It suggests that oppositional brand loyalty is another way of sustaining a sense of like-mindedness. Hamer and his researchers use the Coca-Cola and Pepsi debate to illustrate the notion of 'oppositional brand loyalty' - the idea that some consumers express their opposition to a competing brand as a way of expressing their loyalty to their brand. Some consumers express their loyalty to their brand community and acquire a part of its meaning and identity through their opposition to competing brands. Consumers define themselves not only by the brands they consume but also by the brands they do not consume, and in some cases, these consumers extend this behavior and initiate confrontations with users of competing brands. And most of the subsequent studies are similar to such definitions, highlighting that oppositional brand loyalty is formed concerning their competing brands, building attitudes in their own brand communities by expressing an opposing/negative view of the competing brands. Based on this, we can find that consumers develop a positive relationship of affection towards their own brand community and a negative relationship of dislike towards the competitor brand.

Jaidee and his researchers further enriched and refined the definition by exploring the relational component of oppositional loyalty [5]. They explain the need for consumers to demonstrate oppositional loyalty by adding a third component to the brand community, i.e., competing brands, through congruence theory/inoculation theory/Hyde equilibrium theory/cognitive dissonance theory, etc. This allows consumers to shift from dual loyalty to competing brands to triple loyalty, driven by attitudes towards competing brands.

\section{CLASSIFICATION OF INTER-BRAND FAN CONFRONTATION BEHAVIOR}

\subsection{Passive - indirect type}

The passive-indirect type refers to consumers expressing antagonistic behavior by rejecting and avoiding competing brands and marketing activities. This behavior is classified as passive-indirect because consumers do not act against the competitor brand directly but express their negative perceptions indirectly through passive rejection and avoidance. The desire to avoid is defined as the consumer's need to withdraw themselves from any activity with the company, and as long as the consumer has this desire, they will hold a grudge against the competing brand that they cannot forgive [6], and most consumers in brand fan confrontation behavior have this desire to avoid. However, according to experiments conducted by researchers, this desire for avoidance slowly diminishes over time [7].

\subsection{Passive - direct type type}

The passive-direct type refers to direct attacks on competing brands and associates when consumers perceive it as a threat. We classify this behavior as passive-direct because it is a hostile act in which consumers attack a competing brand only after they perceive it poses a threat. This is because consumers are loyal to their brand community, they choose brands as representatives of their self-concept, and there is a strong connection between the brand and the consumer. Therefore, if a competing brand potentially threatens the consumer's chosen brand, the consumer will resist and rebel against the competing brand to defend their chosen brand[8].

\subsection{Active - Indirect type}

The active-indirect type refers to negative word-ofmouth communication from consumers to third-party consumers. Instead of directly targeting competing brands, consumers engage in confrontational behavior by actively making negative referrals to third-party consumers, hence our classification of this behavior as an active-indirect type. Word-of-mouth communication is a social activity. And experiments have shown that consumers are twice as likely to engage in negative word-of-mouth than positive word-of-mouth. Because in highly competitive markets, most customer experiences are positive, so if some consumers spread negative wordof-mouth about a competing brand. This can have a very negative impact on the competing brand. This impact is particularly significant when the competing brand is lowasset [9], [10].

\subsection{Active - direct type}

The proactive-direct type refers to consumers who actively unapologetically disparage competing brands, including actions such as denigration and swearing. The consumer is proactive, directly attacking the competitor brand without preconditions. We, therefore, classify this behavior as an active-direct type. Consumers will build on the strengths of their brand and group through heated discussions and competitive narratives, and proactive antagonistic behavior towards competing brands also serves the interests of the consumer's chosen brand[11] 


\section{FACTORS INFLUENCING THE DEGREE OF ANTAGONISTIC BEHAVIOR OF BRAND FANS}

After we classify brand fans' oppositional behaviors into four types according to the degree of confrontation, this paper will conduct research from each perspective to actively seek the factors that influence brand fans to engage in different confrontational behaviors. Synthesizing the literature, we explore the factors influencing brand fans' oppositional behavior from two major types, as follows.

\subsection{Passive category}

Why do some brand fans choose to passively avoid messages from competing brands when faced with an adverse threat from them, while others prefer to actively defend their chosen brand by spreading negative communications about the competing brand to other consumers? This paper suggests that the factors that lead to the difference in the two behaviors are broad.

\subsubsection{The place of brand fans in the brand community.}

Differences in the status of fans within a brand community can lead to different brand fan confrontation behaviors, and much of this status depends on the level of fan participation and membership in the brand community. Doosje et al. found through their research that natural groups tend to be bound by a consensus on status hierarchies and related differences between them. For example, people with high status in a group are less likely to exaggerate the advantages of their affiliation to gain a positive social identity. Still, relatively low-status group members are more likely to be motivated to use identity protection or external strategies when they encounter external threats. Experiments have shown that low-status groups emphasize group heterogeneity, while high-status groups emphasize homogeneity [12]. It explained that when faced with an adverse threat from a competing brand, lower-status fans will choose to actively spread negative news about the competing brand to defend their chosen brand (emphasizing heterogeneity). In contrast, higher-status fans will decide to passively avoid competing and defend their chosen brand by asserting their own brand (emphasis on homogeneity).

\subsubsection{Brand fans identify with the brand community.}

The strength of brand fans' identification with the brand community can lead to different brand fan antagonistic behaviors [13]. In an essential definition of the self, the self includes personality traits, values, physical attributes, etc., and material objects closely related to the self. For example, consumers identify with brands that evoke the same emotional responses as the intrinsic aspects of the self. In other words, when the brands that consumers identify with (belong to the element of the self) are threatened, people feel the need to protect themselves, just as they would protect their bodies or psyches. And the theory has found that when the group is threatened, participants who identify strongly with the group (consumers who identify strongly) show outward bias. In contrast, participants who do not identify as strongly with the group (i.e., consumers who identify weakly) do not show solid defensive reactions.

\subsubsection{The implicit self-esteem of brand fans}

When threatened, one importance that moderates people's level of defensiveness is one's self-esteem, mainly implicit self-esteem. Implicit self-esteem is an automatic evaluation assessed through implicit measures, whereas external self-esteem is a conscious, rational evaluation [14]. For example, research has found that threats to the brand trigger the same defensive response to self-threat among individuals who identify with a brand. In contrast, when individuals receive negative information about the brand they identify with, those with low implicit self-esteem change their attitude towards the chosen brand more positively than those with high implicit self-esteem. They protect the threatened self by expressing more significant group bias [13].

\subsection{Active category}

When not perceiving a threat from competing brands, consumers also actively build on the strengths of their chosen brands and groups through heated discussions and competitive narratives. Some consumers choose to spread negative word-of-mouth to other consumers, while others directly denigrate competing brands, and this paper identifies the following factors that lead to these two different behaviors

\subsubsection{Engagement of brand fans in brand communities}

Objective consumer involvement in brand communities is one factor that influences the type of brand fan opposition behavior that consumers develop. By collecting and analyzing data on actual involvement and membership behavior in several competing brand communities, researchers have confirmed that brand community involvement and membership duration influence the adoption of preferred brands and competing for brand products, with more involved consumers sticking with their preferred brands. The more engaged consumers are, the more likely they will stick to new products introduced by their preferred brand 
and oppose new products from their competitor brands [11]. When consumers perceive themselves as members of a group, in most cases, consumers actively seek out favourable information about their group and seek or accept negative news about other groups [15]. Therefore, this paper argues that less engaged consumers tend to accept/spread negative news about competing brands, while more engaged consumers will feel this more strongly and will tend to be actively aggressive and directly discredit competing brands, for example, through behaviors such as garbage-talk. [16].

\subsubsection{Self-brand connection (SBC) of brand fans}

The stronger consumers' self-brand association with the selected brand, the stronger their motivation to protect it, thus denigrating the competing brand more directly [2]. Research has found that when consumers feel highly connected to a brand, their behavior towards it is similar to that of their own, and consumers share the same identity. Therefore, highly connected individuals will actively and directly defend their brand. In extreme cases, antagonizing/disparaging competing brands can even bring pleasure to consumers in certain brand communities [17].

\section{THE IMPACT OF INTER-BRAND FAN CONFRONTATION BEHAVIOR}

This paper describes the impact of inter-brand fan confrontation on competing brands and the chosen brand.

\subsection{Impact on competing brands}

Researchers have found that in situations where a consumer's chosen brand is the first to launch a new product and its competitor brand is the second to launch a new product, oppositional loyalty makes consumers more inclined to buy their chosen brand's product and less likely to buy the competitor brand's product by adopting a hostile attitude towards it. Not only does this result in the competing brand losing the advantage of gaining market share, but the presence of a large number of consumers who are reluctant to adopt the competing brand's products can negatively affect the competing brand [11]. Opposing, denigrating, and swearing behavior towards the competing brand in inter-brand fan confrontation can lead to a tarnished image of the competing brand, which not only reduces the loyalty of consumers in the competing brand's community but also causes potential customers of the brand to waver in their purchasing decisions, which in turn hinders the competing brand from expanding its cus.

\subsection{Impact on the chosen brand}

Inter-fan rivalry behavior helps to promote new products of the chosen brand. Consumer resistance to new products launched by competing brands favouring the chosen brand's latest products strongly contributes to the expansion of the market for the chosen brand's latest products [11]. Furthermore, the positive word-of-mouth marketing among fans motivates consumers to make purchases and may also trigger further word-of-mouth marketing and social media activities, effectively expanding the market power of the chosen brand and increasing its value.

The inventor-brand fan rivalry behavior is conducive to promoting the spread of brand culture. In addition, the comparison of competing brands makes the culture between brands spread faster. For example, in a competition between Coca-Cola and Pepsi, consumers can often be very clever in creating and designing videos, images, and segments to express more graphically why they support the brand using its advertisements, slogans, spokespeople, etc. This is very conducive to the spread of brand culture and makes consumers walking advocates for the brand.

Confrontational behavior among brand fans can increase customer loyalty. Because no matter what measures competitors take, consumers of that brand will still stick to the brand's products due to oppositional loyalty, it is difficult for competitors to convert the brand's fans into their own customers. Therefore, good customer loyalty contributes to the brand image and increases the brand's attractiveness. Furthermore, positive feedback from consumers about the chosen brand, as shown in the confrontational behavior among brand fans, is beneficial in converting potential customers of that brand into real consumers, as consumers tend to consider the opinions of their peers/authentic feedback from consumers as more trustworthy than the information provided by the company [18].

\section{CONCLUSION}

By reviewing the above literature, this paper has systematically categorized brand fan confrontation and summarised the factors and influences that lead it. This is significant to the analysis of inter-brand fan confrontation behavior and will help provide better marketing insights to companies. However, there is still some room for further research on brand-fan confrontation. This paper argues that there is scope to further explore whether brands should manage this type of fan confrontation. Much of the literature has focused on the impact of this behavior on brands. Still, there is a lack of research on whether two competing brands should take appropriate measures to manage inter-brand fan confrontation and how this can be controlled in the 
most favourable direction for the brand, which is worthy of further study to assist brands in developing sound brand management strategies.

\section{AUTHORS' CONTRIBUTIONS}

Conceptualization and discussion were elaborated by Jiada Chen and Simin Ma; methodology and results were coloured by Jiada Chen; the theoretical background was coloured by Simin Ma. All authors have read and agreed to the published version of the manuscript.

\section{ACKNOWLEDGMENTS}

This project is supported by Jinan University National Innovation and Entrepreneurship Training Program For Undergraduate (NO. 202110559024 、 202110559022).

\section{REFERENCES}

[1] S. M. McKelvey and others, "Coca-Cola vs. PepsiCo-A" Super" Battleground for the Cola Wars?," Sport Marketing Quarterly, vol. 15, no. 2, p. 114, 2006.

[2] F. Marticotte, M. Arcand, and D. Baudry, "The impact of brand evangelism on oppositional referrals towards a rival brand," Journal of Product \& Brand Management, vol. 25, no. 6, 2016.

[3] Y.-F. Kuo and J.-R. Hou, "Oppositional brand loyalty in online brand communities: perspectives on social identity theory and consumer-brand relationship," Journal of Electronic Commerce Research, vol. 18, no. 3, p. 254, 2017.

[4] L. O. Hamer and others, "Us versus them: oppositional brand loyalty and the cola wars," ACR North American Advances, vol. 28, no. 1, pp. 355361, 2001.

[5] A. Djedidi and others, "Individual oppositional loyalty: Are loyalty and resistance two sides of the same coin?," 2013.

[6] M. E. McCullough, F. D. Fincham, and J.-A. Tsang, "Forgiveness, forbearance, and time: the temporal unfolding of transgression-related interpersonal motivations.," Journal of personality and social psychology, vol. 84, no. 3, p. 540, 2003.

[7] Y. Grégoire, T. M. Tripp, and R. Legoux, "When Customer Love Turns into Lasting Hate: The Effects of Relationship Strength and Time on Customer Revenge and Avoidance," Journal of Marketing, vol. 73, no. 6, pp. 18-32, Nov. 2009, doi: 10.1509/jmkg.73.6.18.
[8] M. Demirbag-Kaplan, C. Yildirim, S. Gulden, and D. Aktan, "I love to hate you: Loyalty for disliked brands and the role of nostalgia," Journal of Brand Management, vol. 22, no. 2, pp. 136-153, 2015.

[9] M. D. Dalman, S. Chatterjee, and J. Min, "Negative word of mouth for a failed innovation from higher/lower equity brands: Moderating roles of opinion leadership and consumer testimonials," Journal of Business Research, vol. 115, pp. 1-13, 2020.

[10] Y. Zhang, L. Feick, and V. Mittal, "How males and females differ in their likelihood of transmitting negative word of mouth," Journal of Consumer Research, vol. 40, no. 6, pp. 1097-1108, 2014.

[11] S. A. Thompson and R. K. Sinha, "Brand communities and new product adoption: The influence and limits of oppositional loyalty," Journal of marketing, vol. 72, no. 6, pp. 65-80, 2008.

[12] B. Doosje, N. Ellemers, and R. Spears, "Perceived intragroup variability as a function of group status and identification," Journal of experimental social psychology, vol. 31, no. 5, pp. 410-436, 1995.

[13] M. Lisjak, A. Y. Lee, and W. L. Gardner, "When a threat to the brand is a threat to the self: The importance of brand identification and implicit self-esteem in predicting defensiveness," Personality and Social Psychology Bulletin, vol. 38, no. 9, pp. 1120-1132, 2012.

[14] S. L. Koole and T. DeHart, "Self-affection without self-reflection: Origins, models, and consequences of implicit self-esteem.," pp. 21-49, 2007.

[15] T. Hickman and J. Ward, "The dark side of brand community: Inter-group stereotyping, trash talk, and schadenfreude," ACR North American Advances, vol. 34, no. 06, pp. 314-319, 2007.

[16] Z. Hilvert-Bruce and J. T. Neill, 'I'm just trolling: The role of normative beliefs in aggressive behavior in online gaming," Computers in Human Behavior, vol. 102, pp. 303-311, 2020.

[17] S. A. O. Ramírez, C. Veloutsou, and A. MorganThomas, "I hate what you love: brand polarization and negativity towards brands as an opportunity for brand management," Journal of Product \& Brand Management, vol. 28, no. 5, 2019.

[18] P. S. Coelho, P. Rita, and Z. R. Santos, "On the relationship between consumer-brand identification, brand community, and brand loyalty," Journal of Retailing and Consumer Services, vol. 43, pp. 101-110, 2018. 